This may be why they accept the violence perpetrated by ISIS, explains Dawson. "You can become convinced that some uprising is necessary to complete the purification of the world."

According to Zekulin, some recruits may not "subscribe to the ideology but still identify with the goal of establishing a caliphate as a place where Muslims can be safe." In the early days of the conflict, some may have joined ISIS for purely humanitarian reasons, although Zekulin says that's almost impossible to do now.

More often, social justice concerns are part of what makes a person susceptible to ISIS' call. "A high percentage of doctors are driven by altruism and a desire to help others, and the radical message exploits these motives," says Dawson. "People find it amazing that a doctor would want to be part of this ultraviolent group committing atrocities, but on the flipside a lot of what ISIS does looks like humanitarian, social welfare and medical work."

Of the dozens of videos, thousands of documents and hundreds of thousands of social media messages ISIS puts out each month, "only about $10 \%$ has to do with violence and fighting," Dawson notes. "The vast majority is about how important and good it is to live under the caliphate, as well as charitable and infrastructure programs, including medical facilities."

Experiences of discrimination can also play into the jihadist pitch, says Amarasingam. He cites the case of a Montreal woman who joined ISIS believing she that would have more opportunity as a doctor in Syria than as a visible Muslim in Quebec.

An American survey of Muslim physicians showed that $24 \%$ frequently experienced religious discrimination in their careers and 14\% were currently experiencing religious discrimination at work.

Even the secular culture of medicine can be alienating, says Amarasingam. "My wife is a pediatrician and going to gatherings there's drinking and free mixing of men and women, which conservative Muslims will say is not what they signed up for."

Whatever factors draw health workers to ISIS, they appear to undergo the same process of radicalization as would-be fighters and other recruits, he says. It may start with a friendship, often formed online. "You can quickly be in direct communication through social media, creating deep and personal bonds with these fighters thousands of miles away."

Online networks also provide a link to local recruiters. In Canada, there are rumors of active recruiters in Calgary and Ottawa. "Very few people have just got up and left by themselves. They're always part of these networks," Amarasingam explains.

The groups are usually disconnected from local mosques, he adds. "One of the first things they do is form private study groups creating an echo chamber for themselves."

\section{No easy solutions}

Top-down efforts to identify radicalization often backfire, notes Amarasin- gam. The UK's Prevent program, which requires teachers, health workers and other public authorities to report people who might be vulnerable to extremism, has been criticized for demonizing Muslims and creating a climate of suspicion.

"Growing a long beard, dropping certain friends or dressing differently may simply be signs that a person is becoming a conservative Muslim," Amarasingam says. "All of a sudden law enforcement steps in and it alienates the broader community."

Grassroots initiatives to foster community and religious tolerance may be more effective, just as after-school basketball programs in Somali communities in Toronto have successfully kept teens out of gangs, he explains.

Adapting such programs for older professionals may not be possible or effective, though. In medical institutions, the concept of "vigilance" might be more appropriate, says Dawson. "The analogy I use is suicide. Because we've educated ourselves, when someone threatens to end their life you take it seriously, you talk to them about it and you get help."

Like suicide, "people will start talking about [radical beliefs and acts] long before they do anything," Dawson adds. According to one study, $58 \%$ of people who committed lone acts of terrorism had told someone about their plans prior to the event. "We've got to become attuned to that and stop being idle bystanders." Lauren Vogel, CMAJ

CMAJ 2016. DOI:10.1503/cmaj.109-5217

\title{
Prisons face hep C-treatment funding crisis
}

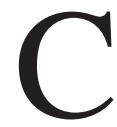

orrectional Service of Canada (CSC) could face a funding shortfall of up to $\$ 100$ million if it adheres to a new standard of care that would see federal inmates infected with hepatitis $\mathrm{C}$ prescribed a new and expensive drug.

Internal government reports, released to CMAJ under the federal access to information law and reviewed by four external experts, appear to indicate that CSC may be delaying treatment for as many as 1750 infected federal inmates. CSC recently released the heavily censored reports to CMAJ, almost ten months past the deadline stipulated under the federal information law.

The funding shortfall is underpinned both by CSC's standard-of- care requirement to use the costly new drugs and a dramatic expansion in the number of inmates potentially treatable with these new drugs, which are better tolerated and more efficacious than the drugs CSC previously used.

In 2014, CSC spent \$4 million to treat about 240 patients with older and cheaper drugs. The new medication will more than triple treatment the cost 
for the same number of inmates, according to a forecast prepared by Henry deSouza, CSC's director general of clinical services and public health, in September 2014.

That translates into a cost of as much as \$15 million annually for those 240 patients, the CSC told CMAJ. "CSC is currently assessing options to address this financial pressure," stated spokeswoman Lori Halfper in an email.

But this number may severely understate the actual cost that CSC faces, say experts who reviewed the data CSC released to CMAJ. That's because new guidelines published last year by the Canadian Association for the Study of the Liver (CASL) recommend that "All patients with chronic [hepatitis $\mathrm{C}$ virus] infection should be considered candidates for antiviral therapy," explains Dr. Peter Ford, a physician who treats patients with HIV and hepatitis $\mathrm{C}$ in federal prisons in Ontario.

The CASL guidelines were subsequently endorsed by the federal Canadian Agency for Drugs and Technologies in Health in December and by Quebec in July.

To adhere to those guidelines, CSC will have to vastly expand the number of inmates it considers for treatment, Ford says. CSC estimates that 2500 inmates are infected, he notes.

As of 2016, according to CSC, the 12-week treatment per patient using the combination therapy Harvoni will average $\$ 67$ 000. At that price, following CASL clinical guidelines will result in a CSC funding shortfall of well over $\$ 100$ million.

CSC Health Services is planning a consultation meeting in early 2016 "with all medical specialists treating CSC offenders with hepatitis C," says Jon Schofield, a communications advisor for CSC.

The CSC acknowledged in an analysis given to CMAJ that "The number eligible for treatment is larger than the old therapy." In recent years about $70 \%$ of infected inmates have been advised by specialists to "wait for a new generation of treatment." In Ontario, where about $30 \%$ of federal inmates are incarcerated, CSC esti-

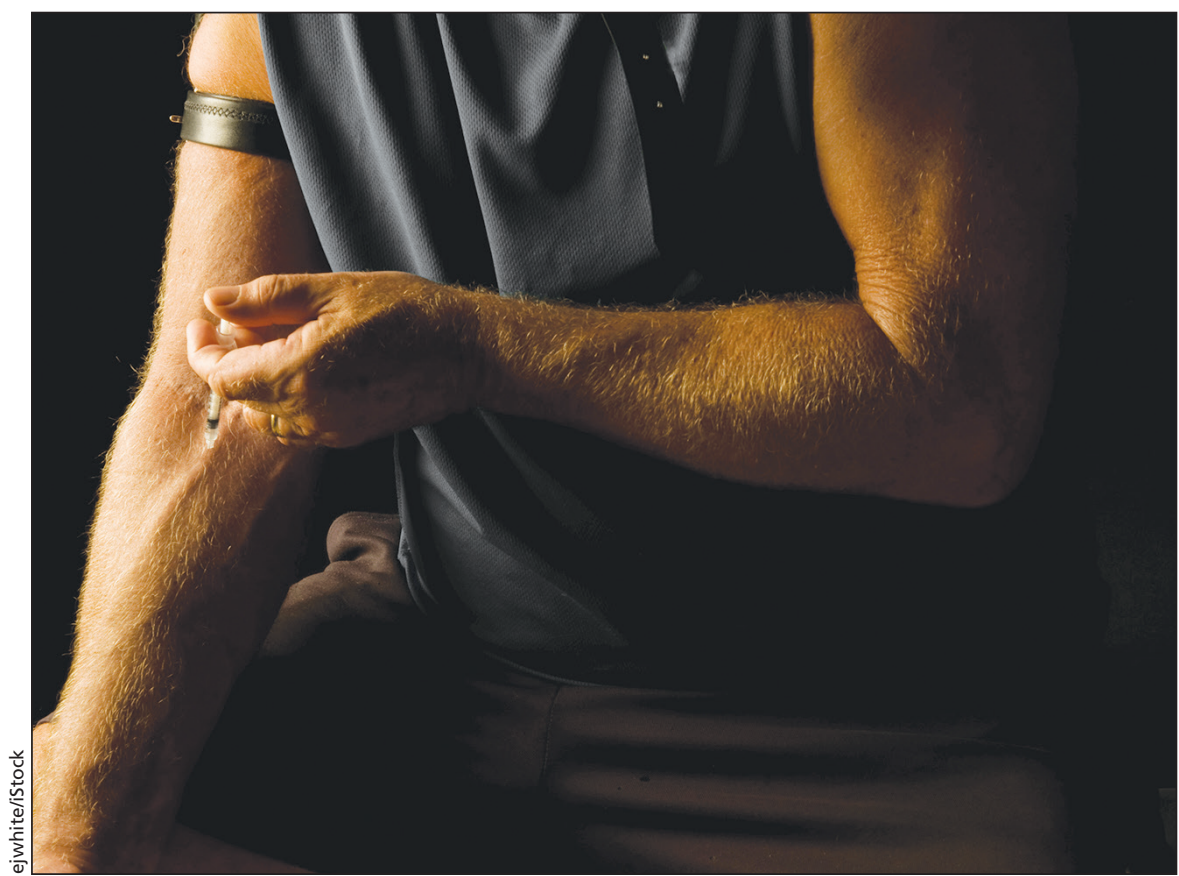

Policy at Correctional Services Canada may be failing to limit the spread of hepatitis C in prisons.

mates that as many as 884 patients await treatment.

Dr. Fiona Kouyoumdjian of St. Michael's Hospital, Centre for Research on Inner City Health in Toronto notes that the very small proportion of inmates currently being treated "raises the question of whether health care is meeting professionally accepted standards, as required by the Corrections and Conditional Release Act."

Kouyoumdjian, and Glenn Betteridge and Adam Cook of the Torontobased Canadian Treatment Action Council, concur with Ford's view that the CASL guidelines compel the CSC to dramatically expand the number of inmates it considers for treatment.

CSC's "Cost Containment Plan," which appears to be based on a hard cap of 240 prisoners treated per year, "is much more restrictive than the approach taken by public drug programs in the community, under which everyone who meets the eligible criteria for hep C drugs can access them," says Betteridge, a lawyer and CTAC policy researcher.

"Restrictions on treatment according to disease stage are no longer tenable for many people living with chronic hep C," says Betteridge. "CSC should get moving and develop an implementation plan to provide the highest standard of care to all prisoners rather than engaging in cost-containment planning and arbitrary rationing of treatment driven by untenably small budgets."

While noting that intravenous drug use is rampant in federal prisons, and needle exchanges forbidden for almost a decade, Ford warns that CSC is "doing little to prevent the spread of hepatitis $\mathrm{C}$ within the institutions. Hepatitis $\mathrm{C}$ in prisons is a major public health issue because people continue to get infected in prison - even CSC admits this - and they will go out and spread the disease."

"Prison represents an important, and often the only, opportunity to treat a significant proportion of hep C positive individuals," Ford says. "What is needed is for CSC to start behaving in a responsible manner, which includes openness rather than secrecy and a willingness to take outside advice about both treatment and prevention. Also there needs to be a significant input of government money not just for drugs, but also to increase the inadequate levels of staffing." — Paul Webster, Toronto, Ont.

CMAJ 2016. DOI:10.1503/cmaj.109-5220 